\section{BRAZIULIAN JOURNAL \\ OF MEDICAL AND BIOLOGICAL RESF.ARCH}

www.bjournal.com.br
ISSN 0100-879X

Volume 42 (11) 993-1118 November 2009

BIOMEDICAL SCIENCES

AND

CLINICAL INVESTIGATION

Braz J Med Biol Res, November 2009, Volume 42(11)1104-1109

Glomerular filtration is reduced by high tidal volume ventilation in an in vivo healthy rat model

A. Luque, M.H.M. Shimizu, L. Andrade, T.R. Sanches and A.C. Seguro

The Brazilian Journal of Medical and Biological Research is partially financed by
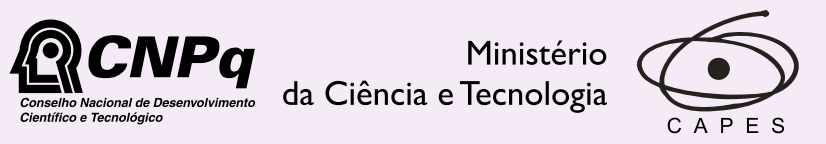

Ministério da Educação

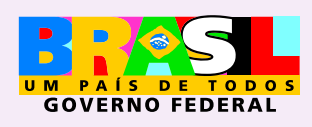

D TAPESP

Institutional Sponsors 


\title{
Glomerular filtration is reduced by high tidal volume ventilation in an in vivo healthy rat model
}

\author{
A. Luque, M.H.M. Shimizu, L. Andrade, \\ T.R. Sanches and A.C. Seguro
}

LIM/12, Departamento de Nefrologia, Faculdade de Medicina, Universidade de São Paulo, São Paulo, SP, Brasil

\begin{abstract}
Mechanical ventilation has been associated with organ failure in patients with acute respiratory distress syndrome. The present study examines the effects of tidal volume $\left(\mathrm{V}_{\mathrm{T}}\right)$ on renal function using two $\mathrm{V}_{\mathrm{T}}$ values $(8 \mathrm{and} 27 \mathrm{~mL} / \mathrm{kg})$ in anesthetized, paralyzed and mechanically ventilated male Wistar rats. Animals were randomized into two groups of 6 rats each: $V_{T} 8\left(V_{T}, 8 \mathrm{~mL} / \mathrm{kg} ; 61.50\right.$ \pm 0.92 breaths/min; positive end-expiratory pressure, $3.0 \mathrm{cmH}_{2} \mathrm{O}$; peak airway pressure (PAW), $11.8 \pm 2.0 \mathrm{cmH}_{2} \mathrm{O}$ ), and $\mathrm{V}_{\mathrm{T}} 27$ $\left(\mathrm{V}_{\mathrm{T}}, 27 \mathrm{~mL} / \mathrm{kg} ; 33.60 \pm 1.56\right.$ breaths/min; positive end-expiratory pressure, none, and PAW, $\left.22.7 \pm 4.0 \mathrm{cmH}_{2} \mathrm{O}\right)$. Throughout the experiment, mean PAW remained comparable between the two groups $\left(6.33 \pm 0.21\right.$ vs $\left.6.50 \pm 0.22 \mathrm{cmH}_{2} \mathrm{O}\right)$. For rats in the $\mathrm{V}_{\mathrm{T}} 27$ group, inulin clearance $\left(\mathrm{mL} \cdot \mathrm{min}^{-1}\right.$. body weight $\left.{ }^{-1}\right)$ decreased acutely after 60 min of mechanical ventilation and even more significantly after $90 \mathrm{~min}$, compared with baseline values $(0.60 \pm 0.05$ and $0.45 \pm 0.05$ vs $0.95 \pm 0.07$; $P<0.001)$, although there were no differences between groups in mean arterial pressure or gasometric variables. In the $V_{T} 8$ group, inulin clearance at $120 \mathrm{~min}$ of mechanical ventilation remained unchanged in relation to baseline values $(0.72 \pm 0.03 \mathrm{vs} 0.80 \pm 0.05)$. The $\mathrm{V}_{T} 8$ and $\mathrm{V}_{\top} 27$ groups did not differ in terms of serum thiobarbituric acid reactive substances $(3.97 \pm 0.27 \mathrm{vs} 4.02 \pm 0.45 \mathrm{nmol} / \mathrm{mL})$ or endothelial nitric oxide synthase expression (94.25 \pm 2.75 vs $96.25 \pm 2.39 \%)$. Our results show that glomerular filtration is acutely affected by high tidal volume ventilation but do not provide information about the mechanism.
\end{abstract}

Key words: Artificial respiration; Kidney; Physiology; Glomerular filtration rate; Wistar rats

\section{Introduction}

Mechanical ventilation has been recently associated with the development of distant organ failure in patients with acute respiratory distress syndrome, causing more deaths than hypoxia among these patients (1). Mechanical ventilation is also a contributing factor to renal failure in trauma patients (2), as well as being a risk factor for dialysis and mortality in the intensive care unit (3). Ventilatory strategy has been correlated with the release of inflammatory mediators, and a lung-protective strategy has been shown to attenuate the local and systemic cytokine response (4), as well as resulting in lower mortality than that seen when conventional ventilation is used (5). Few studies have investigated the effects that the mechanical ventilation strategy per se has on renal function in rats, especially in terms of tidal volume and inulin clearance. The objective of the present study was to explore the hypothesis that the mechanical ventilation can contribute to the impairment of renal function.

\section{Material and Methods}

\section{Animals}

For the purposes of this study, male adult Wistar rats weighing 250 to $450 \mathrm{~g}$ were obtained from the animal facilities of the University of São Paulo School of Medicine. The protocol was approved by the Ethics in Research Committee of the University of São Paulo School of Medicine and all procedures involving animals were carried out in accordance with Health Guide for the Care and Use of Laboratory Animals.

Healthy rats were randomized into two groups: those receiving mechanical ventilation at a tidal volume of $8 \mathrm{~mL} /$ $\mathrm{kg}\left(\mathrm{V}_{\mathrm{T}} 8\right.$ group; $\left.\mathrm{N}=6\right)$, and those receiving mechanical ventilation at a tidal volume of $27 \mathrm{~mL} / \mathrm{kg}\left(\mathrm{V}_{\top} 27\right.$ group; $\left.\mathrm{N}=6\right)$.

Correspondence: A. Luque, Laboratório de Pesquisa Básica LIM/12, Faculdade de Medicina, USP, Av. Dr. Arnaldo, 455, 3ํandar Sala 3310, 01246-000 Paulo, SP, Brasil. Fax: +55-11-3088-2267. E-mail: aleluque@terra.com.br 
The animals were anesthetized with $50 \mathrm{mg} / \mathrm{kg}$ body weight of sodium pentobarbital administered intraperitoneally. The rats were tracheostomized with a 14-gauge tube catheter, and spontaneous breathing in room air was maintained for $90 \mathrm{~min}$ to achieve steady-state inulin levels and $30 \mathrm{~min}$ for inulin monitoring.

The right carotid artery was cannulated with a PE-60 catheter in order to determine mean arterial pressure, as well as to allow blood sampling at different times. The blood samples were used to quantify gas tensions and hemoglobin saturation using a blood gas analyzer and a CO-oximeter, respectively (models $1620 \mathrm{pH} /$ and 682; Instrumentation Laboratory, USA). The left jugular vein was also cannulated with a PE-60 catheter for infusion of inulin and fluids. In order to collect urine samples, the urinary bladder was cannulated with a PE-240 catheter by a suprapubic incision. After $1 \mathrm{~h}$ of spontaneous breathing, the animals were connected to a small animal ventilator (Atlanta ${ }^{\circledR}$; Takaoka, Brazil) at a tidal volume of either 8 or $27 \mathrm{~mL} / \mathrm{kg}$, and immediately received a single intravenous injection of $0.825 \mathrm{mg} / \mathrm{kg}$ pancuronium bromide, an additional one-quarter dose was given if inspiration effort was detected.

\section{Mechanical ventilation parameters}

The respiratory rate was initially set at 55 and 35 breaths/ min, respectively, for the $\mathrm{V}_{\top} 8$ and $\mathrm{V}_{\top} 27$ groups, and was increased or decreased by 5 breaths/min if the levels of $\mathrm{PaCO}_{2}$ moved out of the normal range. The initial levels of the fraction of inspired oxygen $\left(\mathrm{FiO}_{2}\right)$ were set at $50 \%$ using an air/oxygen blender. No additional adjustment was necessary for the $\mathrm{V}_{\top} 8$ group during the experiment. However, $\mathrm{V}_{\mathrm{T}} 27$ group required $5-10 \%$ increases in order to maintain similar $\mathrm{PaO}_{2}$ levels in the two groups during the experiment, especially during the final $30 \mathrm{~min}$. To maintain the mean airway pressure (PAW) comparable between the two groups, positive end-expiratory pressure (PEEP) of 3 $\mathrm{cmH}_{2} \mathrm{O}$ was used for the $\mathrm{V}_{\top} 8$ group, whereas no PEEP was required for the $\mathrm{V}_{\mathrm{T}} 27$ group.

\section{Management of mean arterial pressure}

Mean arterial pressure was measured immediately after the surgical procedures, prior to the inulin clearance studies. If necessary, $10 \mathrm{~mL} / \mathrm{kg} 0.9 \%(\mathrm{w} / \mathrm{v}) \mathrm{NaCl}$ was administered for volume replacement.

\section{Clearance studies}

Following the surgical procedure, a loading dose of inulin $(100 \mathrm{mg} / \mathrm{kg}$ body weight diluted in $0.9 \% \mathrm{NaCl})$ was administered through the jugular vein. Subsequently, a constant infusion of inulin $(10 \mathrm{mg} / \mathrm{kg}$ body weight in $0.9 \%$ $\mathrm{NaCl}$ ) was started and continued at $0.04 \mathrm{~mL} / \mathrm{min}$ throughout the experiment. Five urine samples were collected at 30-min intervals ( 1 sample during spontaneous breathing and 4 samples under mechanical ventilation). Blood samples were obtained at the beginning and at the end of the experiment.
At the end of the experiment, the right kidney was removed and frozen in liquid nitrogen.

Blood and urine inulin was determined by the anthrone method, whereas sodium and potassium concentrations were measured using a flame photometer (model 143; Instrumentation Laboratory). Serum levels of thiobarbituric acid reactive substances (TBARS), glomerular filtration rate (GFR) and expression of endothelial nitric oxide synthase (eNOS) were determined, as was urine osmolality, using an osmometer (model 3D3; Advanced Instruments, USA).

\section{Preparation of kidney samples for eNOS protein expression studies}

Samples of right kidneys from 4 animals of each group were collected and homogenized with a Teflon pestle glass homogenizer (Schmidt and Co., Germany), in ice-cold isolation solution (200 mM mannitol, $80 \mathrm{mM}$ HEPES, $41 \mathrm{mM}$ $\mathrm{KOH}, \mathrm{pH} 7.5)$ containing protease inhibitors ( $5 \mathrm{~mL}$ protease inhibitor cocktail \#P8340, Sigma, USA). The homogenates were centrifuged at low speed $(3000 \mathrm{~g})$ for $15 \mathrm{~min}$ at $4^{\circ} \mathrm{C}$ to remove nuclei and cell debris and the pellets were suspended in isolation solution with protease inhibitors. Protein amounts were determined by the Bradford assay method using bovine serum albumin as standard.

\section{Electrophoresis and immunoblotting}

For evaluation of the eNOS isoform, $100 \mu \mathrm{g}$ total protein from each sample was separated on an $8 \%$ polyacrylamide gel and transferred to a PVDF membrane. Immunoblotting was performed with an antibody (Santa Cruz Biotechnology, USA) to eNOS diluted 1:2000 in Tris-buffered saline (TBS) and $0.1 \%$ Tween. Immunodetection was carried out using the appropriate anti-mouse horseradish peroxidaselinked secondary antibody (Sigma), diluted 1:2000 in TBS and $0.1 \%$ Tween, and an enhanced chemiluminescence kit (Amersham Pharmacia Inc., Sweden).

To control for loading, blots were incubated with actin antibody (1:3000, Santa Cruz Biotechnology) and labeling was visualized with anti-goat horseradish peroxidaseconjugated secondary antibody (1:5000; Sigma).

\section{Determination of thiobarbituric acid reactive substances}

Serum levels of TBARS were determined by the thiobarbituric acid assay. Briefly, a 0.2-mL serum sample was diluted in $0.8 \mathrm{~mL}$ distilled water. Immediately thereafter, 1 $\mathrm{mL} 17.5 \%$ trichloroacetic acid (TCA) and $1 \mathrm{~mL} 0.6 \%$ thiobarbituric acid, $\mathrm{pH} 2$, were added. The sample was then placed in a boiling water bath for $15 \mathrm{~min}$. After the sample had cooled, $1 \mathrm{~mL} 70 \%$ TCA was added and the mixture was allowed to incubate for $20 \mathrm{~min}$. The sample was then centrifuged at $2000 \mathrm{rpm}$ for $15 \mathrm{~min}$. The absorbance of the supernatant was read at $534 \mathrm{~nm}$ against a reagent blank using a spectrophotometer. Serum levels of TBARS, in nanomoles, were calculated using a molar extinction coefficient 
of $1.56 \times 10^{5} \cdot \mathrm{M}^{-1} \cdot \mathrm{cm}^{-1}$ and are reported as $\mathrm{nmol} / \mathrm{mL}$.

\section{Statistical analysis}

Data are reported as means \pm SEM. In order to determine the effect of high tidal volume ventilation on renal function, the $\mathrm{V}_{\mathrm{T}} 8$ group was compared with the $\mathrm{V}_{\mathrm{T}} 27$ group using ANOVA and the Student-Newman-Keuls post-test. We also used $t$-tests as appropriate. The level of significance was set at $P<0.05$. Statistics were performed using dedicated software (GraphPad Prism, version 3.0; USA).

\section{Results}

Although we initially randomized 12 rats, a total of 15 rats (weighing 240-435 g) were studied because two $\mathrm{V}_{\mathrm{T}} 27$ group rats died after 60 min of mechanical ventilation and one $\mathrm{V}_{\mathrm{T}} 8$ group rat died after 90 min of mechanical ventilation. Consequently, we randomized an additional three animals in order to replace those that were lost, thereby maintaining the planned study groups at six rats each. We observed a mortality rate of $14.3 \%$ in the $\mathrm{V}_{\mathrm{T}} 8$ group and $25 \%$ in the $V_{\top} 27$ group. Additional saline infusion to correct hypotension was necessary only for those animals that ultimately did not survive.

In the $\mathrm{V}_{\mathrm{T}} 8$ group, peak inspiratory pressure was $11.8 \pm 2$ $\mathrm{cmH}_{2} \mathrm{O}$ compared with $22.7 \pm 4 \mathrm{cmH}_{2} \mathrm{O}$ in the $\mathrm{V}_{\mathrm{T}} 27$ group. No intrinsic PEEP developed dynamically. Over the course of the experiment, mean PAW did not differ between the two groups $\left(6.33 \pm 0.21\right.$ vs $\left.6.50 \pm 0.22 \mathrm{cmH}_{2} \mathrm{O}\right)$.

Table 1 shows the physiologic variables of the two

Table 1. Changes in physiologic variables over $120 \mathrm{~min}$ of mechanical ventilation with tidal volume of 8 $\mathrm{mL} / \mathrm{kg}\left(\mathrm{V}_{\mathrm{T}} 8\right)$ or $27 \mathrm{~mL} / \mathrm{kg}\left(\mathrm{V}_{\mathrm{T}} 27\right)$.

\begin{tabular}{|c|c|c|c|}
\hline Group/variable & Equilibration & $30^{\prime} \mathrm{MV}$ & 120' MV \\
\hline \multicolumn{4}{|l|}{$\mathrm{V}_{\mathrm{T}} 8$} \\
\hline MAP (mmHg) & $129 \pm 6.00$ & $129.6 \pm 14.67$ & $132.2 \pm 6.76$ \\
\hline $\mathrm{PaO}_{2}$ (Torr) & $79.48 \pm 5.68$ & $199.54 \pm 36.86^{*}$ & $210.22 \pm 21.65^{*}$ \\
\hline $\mathrm{PaCO}_{2}$ (Torr) & $38.22 \pm 6.76$ & $35.96 \pm 8.81$ & $39.4 \pm 7.87$ \\
\hline $\mathrm{pH}$ & $7.37 \pm 0.04$ & $7.36 \pm 0.10$ & $7.33 \pm 0.118$ \\
\hline $\mathrm{BIC}(\mathrm{mmol} / \mathrm{L})$ & $22.4 \pm 1.09$ & $24.32 \pm 2.93$ & $26 \pm 3.99$ \\
\hline $\mathrm{SaO}_{2}(\%)$ & $94 \pm 2.73$ & $95 \pm 3$ & $93 \pm 1.7$ \\
\hline $\mathrm{Hb}(\mathrm{g} / \mathrm{dL})$ & $11.62 \pm 0.76$ & $11.64 \pm 1.50$ & $11.1 \pm 1.04$ \\
\hline $\mathrm{Ht}(\%)$ & $35.92 \pm 2.19$ & $37.26 \pm 3.73$ & $34.2 \pm 3.07$ \\
\hline Lactate $(\mathrm{mmol} / \mathrm{L})$ & $1.12 \pm 0.35$ & $1.4 \pm 0.61$ & $1.58 \pm 0.74$ \\
\hline Urine output (mL/min) & $0.015 \pm 0.002$ & $0.022 \pm 0.07$ & $0.014 \pm 0.03$ \\
\hline $\mathrm{FEH}_{2} \mathrm{O}(\%)$ & $0.36 \pm 0.05$ & $0.37 \pm 0.04$ & $0.29 \pm 0.03$ \\
\hline FENa (\%) & $0.68 \pm 0.30$ & $0.37 \pm 0.19$ & $0.29 \pm 0.07$ \\
\hline FEK (\%) & $35.02 \pm 5.44$ & $23.63 \pm 3.81$ & $21.32 \pm 4.41$ \\
\hline \multicolumn{4}{|l|}{$\mathrm{V}_{\top} 27$} \\
\hline MAP (mmHg) & $122 \pm 13.50$ & $134.4 \pm 4.72$ & $114 \pm 18.01$ \\
\hline $\mathrm{PaO}_{2}$ (Torr) & $79.58 \pm 8.43$ & $190.94 \pm 38.96^{*}$ & $185.2 \pm 19.55^{*}$ \\
\hline $\mathrm{PaCO}_{2}$ (Torr) & $31.14 \pm 7.10$ & $35.8 \pm 4.39$ & $37.48 \pm 6.24$ \\
\hline $\mathrm{pH}$ & $7.38 \pm 0.03$ & $7.33 \pm 0.06$ & $7.35 \pm 0.09$ \\
\hline $\mathrm{BIC}(\mathrm{mmol} / \mathrm{L})$ & $22.98 \pm 2.42$ & $25.26 \pm 3.89$ & $23.88 \pm 4.40$ \\
\hline $\mathrm{SaO}_{2}(\%)$ & $93 \pm 2.3$ & $96 \pm 1.5$ & $91 \pm 1.2$ \\
\hline $\mathrm{Hb}(\mathrm{g} / \mathrm{dL})$ & $14.05 \pm 2.27$ & $12.67 \pm 1.17$ & $11.60 \pm 1.08$ \\
\hline $\mathrm{Ht}(\%)$ & $40.50 \pm 5.05$ & $38.95 \pm 3.54$ & $35.77 \pm 3.39$ \\
\hline Lactate $(\mathrm{mmol} / \mathrm{L})$ & $1.7 \pm 0.74$ & $1.5 \pm 0.27$ & $1.4 \pm 0.44$ \\
\hline Urine output (mL/min) & $0.017 \pm 0.002$ & $0.025 \pm 0.011$ & $0.012 \pm 0.001$ \\
\hline $\mathrm{FEH}_{2} \mathrm{O}(\%)$ & $0.76 \pm 0.27$ & $0.87 \pm 0.24$ & $0.59 \pm 0.05$ \\
\hline FENa (\%) & $1.45 \pm 0.51$ & $1.25 \pm 0.63$ & $0.41 \pm 0.04$ \\
\hline FEK (\%) & $50.77 \pm 15.74$ & $26.68 \pm 8.58$ & $19.61 \pm 1.60$ \\
\hline
\end{tabular}

$30^{\prime} \mathrm{MV}=30$ min mechanical ventilation; $120^{\prime} \mathrm{MV}=120$ min mechanical ventilation; $\mathrm{MAP}=$ mean arterial pressure; $\mathrm{PaO}_{2}=$ oxygen arterial blood gas tension; $\mathrm{PaCO}_{2}=$ carbon dioxide arterial blood gas tension; $\mathrm{BIC}=$ bicarbonate; $\mathrm{SaO}_{2}=$ oxygen hemoglobin saturation; $\mathrm{Hb}=$ hemoglobin; $\mathrm{Ht}=$ hematocrit; lactate = arterial lactate levels; $\mathrm{FEH}_{2} \mathrm{O}=$ fractional excretion of water; $\mathrm{FENa}=$ fractional excretion of sodium; FEK $=$ fractional excretion of potassium. ${ }^{*} \mathrm{P}<0.001 \mathrm{vs}$ equilibration (ANOVA). 


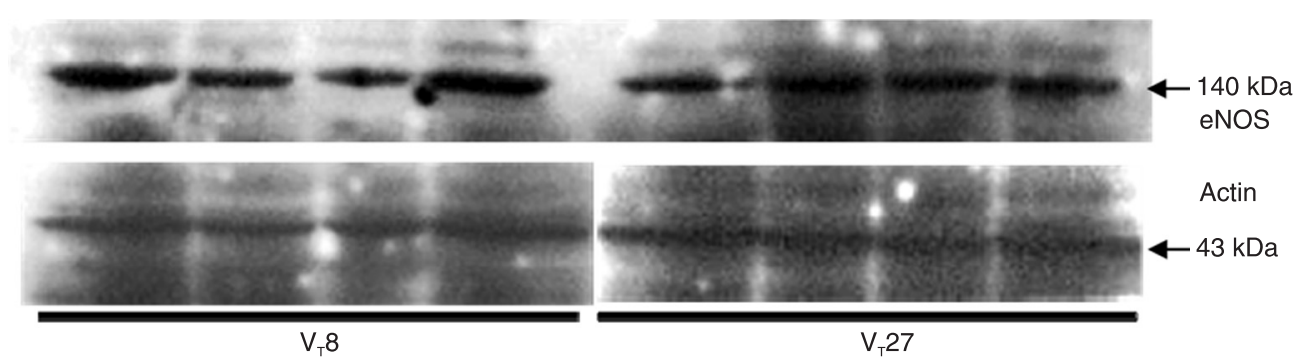

Figure 1. Semiquantitative immunoblotting of samples of right kidney from 4 rats of each group after $2 \mathrm{~h}$ of mechanical ventilation with tidal volumes of $8 \mathrm{~mL} / \mathrm{kg}\left(\mathrm{V}_{\mathrm{T}} 8\right)$ and $27 \mathrm{~mL} / \mathrm{kg}\left(\mathrm{V}_{\mathrm{T}} 27\right)$. Immunoblots that reacted with anti-eNOS antibodies revealed 140-kDa bands. eNOS = endothelial nitric oxide synthase.

groups. In both groups, mean arterial pressure was greater after the administration of the loading dose of inulin than during the immediate postoperative period. This is to be expected because of the volume expansion resulting from the loading dose. However, no subsequent difference in mean arterial pressure was observed between groups. Nevertheless, $V_{\top} 8$ group rats presented only minor variations between inspiration and expiration, whereas $V_{\mathrm{T}} 27$ group rats presented marked temporal variations in blood pressure. Animals were normoxic and normocapnic, with no differences between groups at baseline. As expected, $\mathrm{PaO}_{2}$ increased in both groups after the initiation of mechanical ventilation. These values were comparable for the two groups and remained so throughout the experiment, as did lactate values. There were no significant differences between groups in terms of any other parameters of renal function. Urine output was comparable in the two groups and did not vary significantly over the course of the experiment.

\section{High tidal volume ventilation is associated with decreased glomerular filtration rate}

The results of the clearance studies showed no significant change in inulin clearance for the $\mathrm{V}_{\mathrm{T}} 8$ group during the experiment (baseline, $0.72 \pm 0.03$ vs $120 \mathrm{~min}, 0.80 \pm 0.05$ ). In the $V_{\top} 27$ group inulin clearance showed no difference in the first $30 \mathrm{~min}$ of mechanical ventilation $(0.87 \pm 0.06)$ compared to baseline but was significantly lower after 60 min of mechanical ventilation than at baseline $(0.60 \pm 0.05$ vs $0.95 \pm 0.07 ; P<0.001$ ), indicating acute kidney injury. This difference became even more pronounced after 90 and 120 min of ventilation $(0.45 \pm 0.05$ and $0.40 \pm 0.04$, respectively; $\mathrm{P}<0.001$ ).

\section{TBARS and mechanical ventilation strategy}

No difference in serum values was observed between the $\mathrm{V}_{\top} 8$ and $\mathrm{V}_{\mathrm{\top}} 27$ groups (3.97 \pm 0.27 and $4.02 \pm 0.45$ $\mathrm{nmol} / \mathrm{mL}$, respectively).

\section{Mechanical ventilation and eNOS}

Densitometric analysis revealed no significant difference between the $\mathrm{V}_{\top} 8$ and $\mathrm{V}_{\top} 27$ groups in terms of expression of eNOS protein in the kidney $(94.25 \pm 2.75$ and $96.25 \pm$ $2.39 \%$, respectively). Semiquantitative immunoblotting of right kidney samples after $2 \mathrm{~h}$ of mechanical ventilation can be seen in Figure 1.

\section{Discussion}

There is growing interest in the potential relationship between mechanical ventilation and the failure of distant organs (6-11). Kidney function has been addressed in a number of studies. Most of them, however, have investigated the effects of initiating positive pressure rather than the effects of specific ventilation strategies. For instance, urine output has been extensively studied in relation to the institution of positive pressure. However, the effect of tidal volume on GFR, as determined using inulin clearance, is less clear, especially in rat models (12).

The two tidal volume strategies employed in the present study were chosen on the basis of pilot experiments. Since variations in mean PAW can affect venous return and mean arterial pressure, we considered it fundamental to maintain these values stable in both groups. PEEP of 3 $\mathrm{cmH}_{2} \mathrm{O}$ was provided to the $\mathrm{V}_{\top} 8$ group in order to equalize the two groups in terms of mean PAW, which therefore did not differ between groups.

The maintenance of mean arterial pressure preserves regional blood flow. In the present study, mean arterial pressure was comparable between groups, despite being above normal compared to the rats not on ventilation. This was expected due to the volume expansion performed at the beginning of the study (loading dose of inulin). When intra-thoracic pressure increases rapidly, central blood volume decreases (13). Therefore, in the present study, variations in cardiac output and in the regional distribution of blood might have occurred during the inspiratory phase, especially in the $\mathrm{V}_{\mathrm{T}} 27$ group. Studying dogs ventilated for 30 min with a PEEP of $14 \mathrm{cmH}_{2} \mathrm{O}$, Dorinsky and Whitcomb (14) demonstrated a $30 \%$ increase in renal blood flow in relation to the baseline value and a $60 \%$ reduction in hepatic blood flow. Assuming that these conditions are applicable to rats, this would imply possible variations in renal blood flow in the $\mathrm{V}_{\mathrm{T}} 27$ group. 
Our two groups effectively exhibited different tidal volumes. However, due to the adjustment of the respiratory rate and maintenance of the minute volume, it was not possible to detect significant variations in $\mathrm{PaO}_{2}, \mathrm{PaCO}_{2}$ or any other physiological variable investigated.

In the $\mathrm{V}_{\top} 27$ group studied here, there was an acute reduction in inulin clearance after 60 min on mechanical ventilation, and this reduction became more marked after $90 \mathrm{~min}$. This reduction in inulin clearance translates to a reduction in GFR and consequent acute kidney injury. These findings are not in agreement with those of Hoag et al. (15), who recently investigated the effect of lung injury induced by acid aspiration on kidney function in dogs ventilated at a tidal volume of $25 \mathrm{~mL} / \mathrm{kg}$ and found no difference between those with and without acid-induced lung injury in terms of inulin clearance. This difference might be explained by the different animal models studied (dogs versus rats). Ventilation at a high tidal volume might have less aggressive effects on larger animals. However, Imai et al. (16) found that injurious ventilation strategies induced apoptosis of kidney cells and led to an increase in the levels of biochemical markers of kidney dysfunction. Kidney function underwent changes after $8 \mathrm{~h}$ of injurious ventilation, measured by the concentration of creatinine in the plasma rather than by inulin clearance.

Both groups were maintained under the same physiological conditions in order to isolate the effect of tidal volume per se. $\mathrm{V}_{\top} 27$ group rats presented marked temporal variations in blood pressure and probably underwent renal vascular adaptations and impairment in GFR as suggested by Valenza et al. (17).

The fact that we observed no changes in kidney function

\section{References}

1. Montgomery AB, Stager MA, Carrico CJ, Hudson LD. Causes of mortality in patients with the adult respiratory distress syndrome. Am Rev Respir Dis 1985; 132: 485-489.

2. Vivino G, Antonelli M, Moro ML, Cottini F, Conti G, Bufi M, et al. Risk factors for acute renal failure in trauma patients. Intensive Care Med 1998; 24: 808-814.

3. Chertow GM, Lazarus JM, Paganini EP, Allgren RL, Lafayette RA, Sayegh MH. Predictors of mortality and the provision of dialysis in patients with acute tubular necrosis. The Auriculin Anaritide Acute Renal Failure Study Group. J Am Soc Nephrol 1998; 9: 692-698.

4. Ranieri VM, Suter PM, Tortorella C, De Tullio R, Dayer JM, Brienza A, et al. Effect of mechanical ventilation on inflammatory mediators in patients with acute respiratory distress syndrome: a randomized controlled trial. JAMA 1999; 282: 54-61.

5. Ventilation with lower tidal volumes as compared with traditional tidal volumes for acute lung injury and the acute respiratory distress syndrome. The Acute Respiratory Distress Syndrome Network. N Engl J Med 2000; 342: 1301-1308.

6. Kredel M, Muellenbach RM, Brock RW, Wilckens HH, Bred- other than that related to GFR allows us to speculate that high tidal volume leads to alterations in the mechanisms related to glomerular filtration. Qvist et al. (18) partially validated the hemodynamic aspects related to positive pressure in a canine model, demonstrating that stable cardiac output in the presence of positive pressure is not associated with a reduction in GFR or in urine output. Both groups were under the same physiological conditions resulting from the positive pressure, although cardiac output was not measured. Research has shown that high tidal volume induces distal organ injury and systemic proinflammatory response, suggesting that inflammatory rather than purely hemodynamic alterations are involved in distal organ injury (19).

In the present study, eNOS expression in the kidney was comparable for the two groups. It is not clear which mechanism connects pulmonary distension to distant organs (20). Even assuming a tendency of renal blood flow to remain constant and possible variations in renal perfusion pressure by intrinsic mechanisms, we can state that GFR was affected by the ventilation strategy adopted.

Serum TBARS are markers of lipid peroxidation and, consequently, of oxidative stress. Since levels of TBARS were comparable for the two groups, we can conclude that 120 min of mechanical ventilation was insufficient to increase oxidative stress at either of the tidal volumes employed.

\section{Acknowledgments}

We would like to thank Marcelo Costa, Research Division of Takaoka-Brazil, for excellent technical assistance and Jeff Boyles, chief editor of Precise Editing, for English support. Research supported by FAPESP (\#08/57243-4).

erlau J, Roewer N, et al. Liver dysfunction after lung recruitment manoeuvres during pressure-controlled ventilation in experimental acute respiratory distress. Crit Care 2007; 11: R13.

7. Slutsky AS. Ventilator-induced lung injury: from barotrauma to biotrauma. Respir Care 2005; 50: 646-659.

8. Kuiper JW, Groeneveld AB, Slutsky AS, Plotz FB. Mechanical ventilation and acute renal failure. Crit Care Med 2005; 33: 1408-1415.

9. Plotz FB, Slutsky AS, van Vught AJ, Heijnen CJ. Ventilatorinduced lung injury and multiple system organ failure: a critical review of facts and hypotheses. Intensive Care Med 2004; 30: 1865-1872.

10. Gurkan OU, O'Donnell C, Brower R, Ruckdeschel E, Becker PM. Differential effects of mechanical ventilatory strategy on lung injury and systemic organ inflammation in mice. Am J Physiol Lung Cell Mol Physiol 2003; 285: L710-L718.

11. Slutsky AS, Tremblay LN. Multiple system organ failure. Is mechanical ventilation a contributing factor? Am J Respir Crit Care Med 1998; 157: 1721-1725.

12. Pannu N, Mehta RL. Effect of mechanical ventilation on the 
kidney. Best Pract Res Clin Anaesthesiol 2004; 18: 189203.

13. Sykes MK, Adams AP, Finlay WE, McCormick PW, Economides $A$. The effects of variations in end-expiratory inflation pressure on cardiorespiratory function in normo-, hypo- and hypervolaemic dogs. Br J Anaesth 1970; 42: 669-677.

14. Dorinsky PM, Whitcomb ME. The effect of PEEP on cardiac output. Chest 1983; 84: 210-216.

15. Hoag JB, Liu M, Easley RB, Britos-Bray MF, Kesari P, Hassoun $\mathrm{H}$, et al. Effects of acid aspiration-induced acute lung injury on kidney function. Am J Physiol Renal Physiol 2008; 294: F900-F908.

16. Imai $\mathrm{Y}$, Parodo J, Kajikawa O, de Perrot M, Fischer S, Edwards V, et al. Injurious mechanical ventilation and endorgan epithelial cell apoptosis and organ dysfunction in an experimental model of acute respiratory distress syndrome. JAMA 2003; 289: 2104-2112.
17. Valenza F, Sibilla S, Porro GA, Brambilla A, Tredici S, Nicolini $G$, et al. An improved in vivo rat model for the study of mechanical ventilatory support effects on organs distal to the lung. Crit Care Med 2000; 28: 3697-3704.

18. Qvist J, Pontoppidan H, Wilson RS, Lowenstein E, Laver MB. Hemodynamic responses to mechanical ventilation with PEEP: the effect of hypervolemia. Anesthesiology 1975; 42: 45-55.

19. Nin N, Penuelas O, de Paula M, Lorente JA, FernandezSegoviano P, Esteban A. Ventilation-induced lung injury in rats is associated with organ injury and systemic inflammation that is attenuated by dexamethasone. Crit Care Med 2006; 34: 1093-1098.

20. Agarwal R. Chronic kidney disease is associated with oxidative stress independent of hypertension. Clin Nephrol 2004; 61: 377-383. 